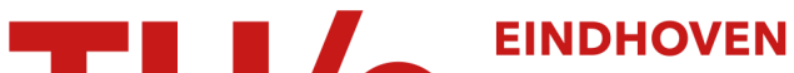 \\ UNIVERSITY OF \\ TECHNOLOGY
}

\section{Flow rate flexibility in complex production departments}

Citation for published version (APA):

Bertrand, J.W. M., \& Ooijen, van, H. P. G. (1991). Flow rate flexibility in complex production departments. International Journal of Production Research, 29(4), 713-724. https://doi.org/10.1080/00207549108930097

DOI:

10.1080/00207549108930097

Document status and date:

Published: 01/01/1991

\section{Document Version:}

Publisher's PDF, also known as Version of Record (includes final page, issue and volume numbers)

\section{Please check the document version of this publication:}

- A submitted manuscript is the version of the article upon submission and before peer-review. There can be important differences between the submitted version and the official published version of record. People interested in the research are advised to contact the author for the final version of the publication, or visit the $\mathrm{DOI}$ to the publisher's website.

- The final author version and the galley proof are versions of the publication after peer review.

- The final published version features the final layout of the paper including the volume, issue and page numbers.

Link to publication

\section{General rights}

Copyright and moral rights for the publications made accessible in the public portal are retained by the authors and/or other copyright owners and it is a condition of accessing publications that users recognise and abide by the legal requirements associated with these rights.

- Users may download and print one copy of any publication from the public portal for the purpose of private study or research.

- You may not further distribute the material or use it for any profit-making activity or commercial gain

- You may freely distribute the URL identifying the publication in the public portal.

If the publication is distributed under the terms of Article 25fa of the Dutch Copyright Act, indicated by the "Taverne" license above, please follow below link for the End User Agreement:

www.tue.nl/taverne

Take down policy

If you believe that this document breaches copyright please contact us at:

openaccess@tue.nl

providing details and we will investigate your claim. 
INT. J. PROD. RES., 1991, VOL. 29, NO. 4, 713-724

\title{
Flow rate flexibility in complex production departments
}

\author{
J. W. M. BERTRAND $\dagger$ and H. P. G. VAN OOIJEN $\dagger$
}

Consider a production situation where it is desirable that the production orders of different product types have different flow rates, independent of their production characteristics such as processing times. Flow rates are mainly determined by the work centre waiting times, thus the product types should have different production order waiting times at the work centres. In this paper we derive a method which makes this possible in a controlled way: given certain values for some parameters the different waiting times (and thus the flow rates) are predictable. By means of simulation this method has been tested for a production situation where only two different flow rates are required per work centre. This simulation study shows that, using a simple balance equation and operation due-date sequencing, it is possible to create different predictable flow rates. It turns out that until a required waiting time reduction for one of the (categories of) products of about $60 \%$ has been achieved a one-to-one relation exists between the scheduled (required) waiting time reduction and the here-called normalized waiting time reduction.

\section{Introduction}

One of the most crucial issues in production control is the control of manufacturing lead times. As has been observed on many occasions (see Kanet 1982, Mather 1984, Plossl 1988), short and reliable lead times are among the fundamental prerequisites for realizing a high market flexibility and a good response to changing market conditions, without having to carry the burden of high stocks of finished products.

In many production situations the production departments have to live with varying routings, different batch sizes, different processing times and varying capacity utilizations at the various work centres in the department. The capacity of the production department should be used to a reasonable degree, say up to $90 \%$ of the bottleneck equipments. This leads to relatively high average throughput times, often to up to 5 to 10 times the total processing time of a work order. Planning and scheduling techniques and priority rules can be used to reduce the average waiting times, but such reductions are limited by the requirement that the deliveries of work orders should also be reliable, that is according to the work order due-dates. As has often been demonstrated, scheduling rules which achieve relatively short throughput times often perform poorly with respect to delivery reliability (see Baker 1974, Conway et al. 1967).

The consequence is that, in complex production systems, a high capacity utilization and a short production throughput time cannot be achieved simultaneously. However, if we have a closer look at production situations in practice, we see that complex production departments where short throughput times are required for all products are rare. In most complex production situations we can see that the work under

Revision received September 1990.

$\dagger$ Eindhoven University of Technology, Faculty of Industrial Engineering, Den Dolech 2, P.O. Box 513, 5600 MB Eindhoven, The Netherlands. 
throughput time requirements is different for different (categories of) products. These differences are due to different costs, different risks and/or different production volumes for the various products. For example:

(1) For products with a relatively low average demand, production may be to customer order and not to stock. To keep the customer order lead time within market requirements it may be necessary to have these products produced with a much shorter work order throughput time than required for products with a high average demand, which are made to stock.

(2) For products which use expensive materials or components it may be advantageous to keep stocks and work-in-process relatively low as compared to the products which use relatively cheap materials. The work orders for the expensive products should, therefore, have short production throughput times.

(3) For components which are required in multicomponent products, and which are manufactured on a make-to-order basis, the allowed manufacturing lead times are the same for all components needed in the same assembly product. These components may widely differ in terms of the required number of manufacturing operations. Thus components requiring many operations should be manufactured at a higher production speed or flow rate (number of operations performed per period) than components requiring only a few operations.

From the above examples we conclude that a production department generally wants to realize simultaneously a high capacity utilization and short work order throughput times for selected product items. In the present paper we present a method which makes this possible. We use widely available knowledge from queueing theory and previous research to derive a potential method. This potential method is checked via systematic computer simulation of an idealized small scale production department.

The outline of the remainder of this paper is as follows. In Section 2 we give a short review of the available literature on throughput time control. Then in Section 3 we derive a method for generating different flow rates for work orders for different (categories of) products. Next, in Section 4 we present the simulation study and in Section 5 we present and discuss the experimental results. Finally, in Section 6 we summarize our findings in a conclusion.

\section{Throughput time control}

In the present paper we consider discrete component manufacturing departments with a functional machine lay-out and a job-shop routing structure. In a functional layout similar machines are grouped into work centres; the job-shop routing structure implies that from each work centre the work orders can flow to a number of other work centres.

In such a production system a major problem encountered in relation to production control is the interaction between throughput times, capacity utilizations and batch sizes: these quantities cannot be chosen independently. For example, a short average throughput time is in general only possible if we work with relatively low capacity utilizations and small batch sizes. Thus for a particular production system the feasible combinations of throughput times, capacity utilizations and batch sizes must be determined. Much research has already been done on the modelling of production systems for this purpose (see Stecke and Solberg 1981, Solberg 1981, Bertrand 1985, 
Karmarkar 1987). A first requirement for throughput time control is that management selects one of the feasible combinations of work order throughput times, capacity utilizations and batch sizes. Management should then control the conditions in the shop such that the selected throughput times can be realized. A generally accepted way to do this is to control the workload in the shop (see Fig. 1). This is also known as input/output planning (see Plossl and Welch 1979, Bertrand and Wortmann 1981, Bechte 1982, Kingsman and Tatsiopoulos 1983). These techniques are based on the calculation of a norm for the (remaining) work-load in the system given a certain required average throughput time. By controlling the (remaining) work-load in the system according to this norm, it is guaranteed that the average throughput time equals the average throughput time norm.

However, in this way we only control the average throughput time and thus the average flow rate for all work orders released to the shop. As shown in the Introduction, there are production situations where we would like to have different (controlled) flow rates for different (categories of) products. In other words, we would like to group products into categories and use a priority procedure such that at the work centres work orders for products in different categories have different controlled thoughput times. Since for the production systems considered the waiting time is the dominant part of the throughput time, we would like to have different waiting times at each work centre. In the next section we show how it is possible to achieve different waiting times, and thus different flow rates, for different (categories of) products.

\section{A method for generating different flow rates}

Suppose we have a number (of categories) of products and that we know the average waiting time we wish to be realized for each product (category). Clearly, to realize different waiting times the decision-maker must be told at what speed the various work orders are expected to get through the work centres. An obvious way to communicate this to the shop floor is to assign operation due-dates to the operations in the routing of a work order, based on the waiting time norms to be realized. Thus, where there are two categories, for work orders which belong to the fast category we assign operation duedates which imply that there is only a little allowance for waiting, whereas for work orders which belong to the slow category we assign operation due-dates which imply a large allowance for waiting. Now the question is whether such a simple heuristic, in combination with a due-date-related sequencing rule, indeed 'forces' the individual



Figure 1. Work-load control technique. 
work orders to flow at the rates implied by these due-dates. As has been demonstrated by Kanet and Hayya (1982), operation due-dates are very effective in this respect: they realize a small variance in the work order lateness. Therefore we used an operation duedate sequencing rule.

Of course using operation due-dates for setting flow rate norms implicitly assumes that the real flow rates per category are in accordance with the flow rate norms used for setting the due-dates (in other words we require realistic due-dates). However, we may expect that not every combination of flow rates can be realized. For instance, suppose we have a single machine shop and two product categories (A and B) each of which has only one product type. Further suppose that the product types have equal production characteristics: they have a Poisson arrival pattern with an arrival rate of one order per hour, and a negative exponential processing time with a mean value of $27 \mathrm{~min}$. Suppose further that the orders are sequenced according to the operation due-dates, where the due-dates are independent of the processing times. Then we know from queueing theory that the expected order waiting time averaged over the orders for both product types is $243 \mathrm{~min}$.

Now suppose that we want different flow rates for the products of categories $A$ and B. In this case it will be impossible to realize at the same time an average waiting time of $50 \mathrm{~min}$ for category A products and an average waiting time of $300 \mathrm{~min}$ for category B products. This can be shown as follows. The average waiting time over all orders is given and the weighted sum of the average waiting times per category equals this given average waiting time. Thus, for the present,

$$
\frac{1}{2} W_{\mathrm{A}}+\frac{1}{2} W_{\mathrm{B}}=W_{\mathrm{T}}
$$

where $W_{\mathrm{A}}$ is the average waiting time for orders for category A products, $W_{\mathrm{B}}$ is the average waiting time for orders for category $\mathrm{B}$ products, and $W_{\mathrm{T}}$ is the total average waiting time.

Evidently the values $W_{\mathrm{A}}=50, W_{\mathrm{B}}=300$ and $W_{\mathrm{T}}=243$ do not fit the above equation. Other values such as $W_{\mathrm{A}}=200$ and $W_{\mathrm{B}}=286$, however, would fit. The above restriction on the flow rates can be stated in more general terms. Consider a production department with $M$ work centres. Suppose we have $K$ different (categories of) products with relative shop arrival rates of the order streams:

$$
\lambda_{i} / \lambda \quad i=1, \ldots, K
$$

where $\lambda_{i}$ is the average number of arrivals of orders for product (category) $i$ per unit time, and $\lambda$ is the total average number of arrivals of orders per unit time.

Furthermore, suppose that the work-load in the shop is controlled via input/output planning such that the actual average waiting time per work centre is equal to $A_{m}$. Then, actual values for the average waiting times per category obey the equation

$$
\lambda_{1} A_{m, 1}+\lambda_{2} A_{m, 2}+\ldots+\lambda_{\mathrm{K}} A_{m, \mathrm{~K}}=\lambda A_{m}
$$

where $A_{m, k}$ is the actual average waiting time for product (category) $k$ and work centre $m, m=1, \ldots, M$ and $A_{m}$ is the actual average waiting time for work centre $m$, $m=1, \ldots, M$.

If we want the actual waiting times to be equal to the norms, or to be in accordance with the required flow rates, it is clear that the same relationship must exist between the 
waiting time norms used in the process of setting operation due-dates. Thus, if $W$ denotes the waiting time norm, we must demand that

$$
\lambda_{1} W_{m, 1}+\lambda_{2} W_{m, 2}+\ldots+\lambda_{k} W_{m, K}=\lambda W_{m}, \quad m=1, \ldots, M
$$

Now the remaining question is the following: suppose (i) we control the work-load in the production department (using input/output planning, see Plossl and Welch (1979), Bertrand and Wortmann (1981), Bechte (1982) and Tatsiopoulos and Kingsman (1983)) such that $A_{m}=W_{m}$ for $m=1, \ldots, M$ (see Eilon and Chowdhury 1976); and (ii) we use operation due-date sequencing with due dates based on waiting time norms which obey eqn. 2 . Is then the actual average waiting time per category equal to the waiting time norm, or will there be a difference? And if there is a difference, how large is it, and how can it be explained and controlled?

If the actual waiting times turn out to be equal to the norms, then we have found a practical method of working with different predictable flow rates. In the following section we deal with finding an answer to these questions. Since it will be difficult, if not impossible, to find these answers by means of mathematical methods (we deal with a closed queueing network in which a dynamic priority rule is used) we used computer simulation to study this problem. This simulation study and the simulation results are discussed in later sections.

\section{The simulation study}

The production model used in our simulation study is a pure job shop (Conway et al. 1967). The shop consists of five unique machines. Order routings are determined upon arrival. The routings are generated so that each machine has an equal probability of being selected as the first machine and after the first operation the probabilities for the order of either leaving the shop or going to another machine are 0-2. However, more than 10 operations are not allowed and, therefore, the generation process is aborted after the tenth operation. Hence the expected number of operations per order is $4 \cdot 463$.

At each work centre processing times are generated from a negative exponential probability density function with a mean value of 1 time unit. Processing times larger than 5 time units are set equal to 5 time units and hence the expected processing time is 0.993 time units. Set-up times and transportation times are considered to be equal to 0 .

For a number of products we aim to give the orders for these products a high flow rate, whereas for the other products we aim to give the orders a low flow rate. Therefore we distinguish only two categories of products: category 1 products (high flow rate), and category 2 products (low flow rate). Each of the two categories has its own random number generator for the determination of the order routings. Per work centre and per category a different random number generator is used for the generation of the processing times.

The shop is loaded via input/output planning using an order release rule based on the remaining work-load (RWL), i.e. the total amount of remaining processing time of all remaining operations in the shop summed over all capacities (comparable to Baker's (1984) loading rule). As long as the RWL does not exceed a certain RWL norm, orders are released every time an order is ready and leaves the shop. Because there is a relation between the RWL and the utilization rate of the shop (see Bertrand and Wortmann 1981), a certain shop utilization can be achieved by choosing the correct RWL norm.

Simulation runs were made on a Burroughs 7700 computer using a specially developed job-shop-simulation package. Each simulation run covers a time span of 
6400 time units. This corresponds with a total of c. 27000 orders for a utilization rate of $84 \%$, a total of c. 29000 orders for a utilization rate of $89 \%$ and a total of c. 30500 orders for a utilization rate of $95 \%$. In order to reduce transient behaviour a number of orders of each product are loaded at the start of a simulation run. The experiments were done by selecting a value for the total average waiting time in relation to the utilization rate implied by the RWL norm and selecting values for the waiting time norms per category in accordance with eqn. 2 . The orders were released to the system and operations were performed at the work centres using the operation due-date sequencing rule. The resulting actual average waiting times were observed and compared to the norms.

The simulation model and the quality of the input/output procedure were validated by running a number of simulations with different seeds for the random number generators. These runs were done with a RWL norm of 80 time units resulting in a shop utilization rate of $c .84 \%$. From the results of these five simulation runs we calculated an average FCFS waiting time of 18.45 time units with a variance of 0.36 time units. Using simple probabilistic theory the average remaining work-load per order in the shop is 3.77 time units. Therefore, a RWL norm of 80 time units corresponds to c. 21 orders present in the shop. Since the shop consists of five identical work centres (as a result of the transition probabilities, equal processing times, etc.) we may conclude that, on average, each work centre has a queue of $4 \cdot 2$ orders (including the one being processed). The expected number of operations per order is 4.463 (due to truncation) so, theoretically, the average shop waiting time is equal to $4.463 \times 4.2 \times 0.993=18.61$ time units. This corresponds quite well to the average waiting time of $18.4 \overline{5}$ time units calculated from the results of the five simulation runs.

\section{Experimental settings and results}

In all the simulations done the work centres have identical characteristics (such as utilization rate, etc.), so we can omit the work centre subscript from the equations.

The first simulation experiments were done with a value of the RWL norm such that the shop utilization rate was $c .84 \%$ and such that there was an equal average number of arrivals of orders per time unit for the two product categories $\left(\lambda_{1}=\lambda_{2}\right)$. The waiting time norms given to the orders of the different categories must then be chosen such that (using eqn. 2)

$$
\frac{1}{2} W_{1}+\frac{1}{2} W_{2}=W
$$

The simulations were performed for a number of values of $W_{1}$ and $W_{2}$. We gradually reduced $W_{1}$ from $W$ to zero in steps of $0.2 W$.

The same type of simulation was then carried out for the situation where the arrival rate for category 2 production orders is twice the arrival rate for category 1 production orders $\left(\lambda_{1}=\frac{1}{2} \lambda_{2}\right)$. In this case eqn. 2 gives

$$
\frac{1}{3} W_{1}+\frac{2}{3} W_{2}=W
$$

The last set of simulations with this utilization rate was done for the case where the arrival rate for category 2 production orders is four times the arrival rate for category 1 production orders $\left(\lambda_{1}=\frac{1}{4} \lambda_{2}\right)$. In this case eqn. 2 gives

$$
\frac{1}{5} W_{1}+\frac{4}{5} W_{2}=W
$$

The results obtained from the simulations are listed in Table 1 . In this table the second column gives the total norm waiting times based on the work centre norm waiting times 


\begin{tabular}{|c|c|c|c|c|c|c|c|}
\hline \multirow[b]{2}{*}{$W_{1}$} & \multirow{2}{*}{$\begin{array}{c}\text { Norm } \\
\text { waiting } \\
\text { time, } \\
\text { category } 1\end{array}$} & \multicolumn{2}{|c|}{$\lambda_{1}=\lambda_{2}$} & \multicolumn{2}{|c|}{$\lambda_{1}=\frac{1}{2} \lambda_{2}$} & \multicolumn{2}{|c|}{$\lambda_{1}=\frac{1}{4} \lambda_{2}$} \\
\hline & & $\begin{array}{c}\text { Category } \\
1\end{array}$ & $\begin{array}{c}\text { Category } \\
2\end{array}$ & $\begin{array}{c}\text { Category } \\
1\end{array}$ & $\begin{array}{c}\text { Category } \\
2\end{array}$ & $\begin{array}{c}\text { Category } \\
1\end{array}$ & $\begin{array}{c}\text { Category } \\
2\end{array}$ \\
\hline $1.0 \mathrm{~W}$ & $17 \cdot 63$ & $17 \cdot 75$ & $17 \cdot 89$ & $18 \cdot 16$ & 18.09 & 17.65 & $18 \cdot 12$ \\
\hline $0.8 W$ & $14 \cdot 10$ & $14-82$ & $20 \cdot 78$ & $15 \cdot 33$ & $19 \cdot 44$ & $15 \cdot 01$ & $18 \cdot 71$ \\
\hline $0.6 \mathrm{~W}$ & $10 \cdot 58$ & $12 \cdot 25$ & $23 \cdot 47$ & $12 \cdot 51$ & $20 \cdot 82$ & $12 \cdot 31$ & $19 \cdot 27$ \\
\hline $0-4 W$ & $7 \cdot 05$ & $9 \cdot 83$ & $25 \cdot 88$ & $10 \cdot 10$ & $22 \cdot 02$ & 9.82 & $19 \cdot 88$ \\
\hline $0 \cdot 2 W$ & $3 \cdot 53$ & 8.04 & $27 \cdot 93$ & 8.03 & $23 \cdot 12$ & 7.72 & $20 \cdot 33$ \\
\hline $0.0 \mathrm{~W}$ & 0.00 & 6.99 & $29 \cdot 02$ & $6 \cdot 57$ & $23 \cdot 82$ & $6 \cdot 28$ & $20 \cdot 68$ \\
\hline
\end{tabular}

Table 1. Average shop waiting times for different norm waiting times and different ratios $\lambda_{1} / \lambda_{2}$ : utilization rate $84 \%$.

\begin{tabular}{|c|c|c|c|c|c|c|c|}
\hline \multirow[b]{2}{*}{$W_{1}$} & \multirow{2}{*}{$\begin{array}{c}\text { Norm } \\
\text { waiting } \\
\text { time, } \\
\text { category } 1\end{array}$} & \multicolumn{2}{|c|}{$\lambda_{1}=\lambda_{2}$} & \multicolumn{2}{|c|}{$\lambda_{1}=\frac{1}{2} \lambda_{2}$} & \multicolumn{2}{|c|}{$\lambda_{1}=\frac{1}{4} \lambda_{2}$} \\
\hline & & $\begin{array}{c}\text { Category } \\
1\end{array}$ & $\begin{array}{c}\text { Category } \\
2\end{array}$ & $\begin{array}{c}\text { Category } \\
1\end{array}$ & $\begin{array}{c}\text { Category } \\
2\end{array}$ & $\begin{array}{c}\text { Category } \\
1\end{array}$ & $\begin{array}{c}\text { Category } \\
2\end{array}$ \\
\hline $1.0 \mathrm{~W}$ & $29 \cdot 52$ & 28.90 & $29 \cdot 11$ & $29 \cdot 37$ & $29 \cdot 77$ & $29 \cdot 10$ & $30-13$ \\
\hline $0.8 W$ & $23 \cdot 62$ & $24 \cdot 07$ & $34 \cdot 52$ & $24 \cdot 59$ & $32 \cdot 17$ & $24 \cdot 65$ & $31 \cdot 16$ \\
\hline $0.6 \mathrm{~W}$ & $17 \cdot 71$ & $19 \cdot 24$ & $39 \cdot 36$ & $19 \cdot 85$ & $34 \cdot 50$ & $19 \cdot 74$ & $32 \cdot 10$ \\
\hline $0.4 W$ & $11 \cdot 81$ & $15 \cdot 03$ & $43 \cdot 82$ & $15 \cdot 37$ & $36 \cdot 73$ & $15 \cdot 42$ & $33 \cdot 21$ \\
\hline $0 \cdot 2 W$ & 5.90 & $11 \cdot 39$ & $47 \cdot 56$ & $11 \cdot 44$ & $38 \cdot 72$ & $11 \cdot 48$ & $34 \cdot 10$ \\
\hline $0.0 \mathrm{~W}$ & 0.00 & 9.02 & $50-45$ & $8 \cdot 68$ & $40 \cdot 25$ & $8 \cdot 62$ & $34 \cdot 85$ \\
\hline
\end{tabular}

Table 2. Average shop waiting times for different norm waiting times and different ratios $\lambda_{1} / \lambda_{2}$ : utilization rate $89 \%$.

\begin{tabular}{|c|c|c|c|c|c|c|c|}
\hline \multirow[b]{2}{*}{$W_{1}$} & \multirow{2}{*}{$\begin{array}{c}\text { Norm } \\
\text { waiting } \\
\text { time, } \\
\text { category } 1\end{array}$} & \multicolumn{2}{|c|}{$\lambda_{1}=\lambda_{2}$} & \multicolumn{2}{|c|}{$\lambda_{1}=\frac{1}{2} \lambda_{2}$} & \multicolumn{2}{|c|}{$\lambda_{1}=\frac{1}{4} \lambda_{2}$} \\
\hline & & $\begin{array}{c}\text { Category } \\
1\end{array}$ & $\begin{array}{c}\text { Category } \\
2\end{array}$ & $\begin{array}{c}\text { Category } \\
1\end{array}$ & $\begin{array}{c}\text { Category } \\
2\end{array}$ & $\begin{array}{c}\text { Category } \\
1\end{array}$ & $\begin{array}{c}\text { Category } \\
2\end{array}$ \\
\hline $1.0 \mathrm{~W}$ & 54.63 & $54 \cdot 31$ & $55 \cdot 11$ & 54.01 & $55 \cdot 19$ & 52.05 & $55 \cdot 15$ \\
\hline $0.8 \mathrm{~W}$ & $43 \cdot 70$ & 44.69 & $64 \cdot 81$ & 44.49 & $59 \cdot 96$ & 43.74 & $57 \cdot 57$ \\
\hline $0.6 W$ & $32-78$ & $35 \cdot 35$ & $74 \cdot 13$ & $35 \cdot 19$ & $64 \cdot 69$ & $34 \cdot 84$ & $59 \cdot 77$ \\
\hline $0.4 W$ & $21 \cdot 85$ & $26 \cdot 39$ & $82 \cdot 68$ & $26 \cdot 28$ & $69 \cdot 27$ & $26 \cdot 52$ & $61 \cdot 93$ \\
\hline $0.2 W$ & $10 \cdot 93$ & 18.57 & $90-49$ & $18-15$ & $73 \cdot 21$ & $18 \cdot 62$ & $63 \cdot 84$ \\
\hline $0 \cdot 0 \mathrm{~W}$ & 0.00 & $13 \cdot 14$ & 96.43 & $12 \cdot 43$ & $76 \cdot 29$ & $12 \cdot 41$ & $65 \cdot 30$ \\
\hline
\end{tabular}

Table 3. Average shop waiting times for different norm waiting times and different ratios $\lambda_{1} \lambda_{2}$ : utilization rate $95 \%$.

which were used to calculate the operation due-dates for the category 1 production orders.

All the above-mentioned simulations were performed using a vaiue for the $\mathrm{RWL}$ norm that generated a $84 \%$ shop utilization rate. All simulations were then repeated with other values for the RWL norm in order to create higher values for the shop utilization rate, i.e. a utilization rate of $89 \%$ and a utilization rate of $95 \%$. Because eqns (3) to (5) are independent of the utilization rate they are also valid in these simulations. The results for utilization rates of $89 \%$ and $95 \%$ are summarized in Tables 2 and 3. 


\section{Discussion of results}

As a performance measure we initially used the average shop waiting time per product category for different combinations of norm waiting times per product category and compared these with the average FCFS waiting time. However, whatever combination of norm waiting times is used, the minimum waiting time that can be obtained for orders of category 1 products has a lower bound $>0$. The value of this lower bound depends on the relative number of orders in category 1 . This minimum waiting time is achieved if we use absolute priority categories: products in a certain category always have priority over products in the lower priority categories; it depends, however, on the sequencing rule used within the categories (see Conway $e t$ al. 1967). Because there is a minimum waiting time of $>0$ there will be a systematic deviation between the waiting time norm and the observed average waiting time. Therefore, we adapted the performance measure to account for this effect. We now compare the actual reduction in waiting time to the maximum reduction that can be obtained. This maximum reduction is equal to the FCFS waiting time minus the minimum waiting time that can be obtained by using absolute priority categories.

In the present simulation study of two product categories we measured:

(1) the average (FCFS) waiting time, $A$;

(2) the 'absolute priority' waiting times, $\mathrm{PRW}_{i}(i=1,2)$; and

(3) the waiting times for the different categories when using the ODD sequencing rule and due-dates based on waiting time norms which obey eqn. 2 , ODW $i$ $(i=1,2)$.

Clearly, $\mathrm{PRW}_{i} \leqslant \mathrm{ODW}_{i} \leqslant A$. The $\mathrm{PRW}$ values for the simulated situations are given in Table 4.

Next we calculated the waiting time reduction for product category $i$, as a percentage of the largest possible reduction in the waiting time

$$
\left(A-\mathrm{ODW}_{i}\right) /\left(A-\mathrm{PRW}_{i}\right) ; \quad i=1,2
$$

We call this the normalized waiting time reduction. The norm waiting time reduction was also expressed as a percentage of the largest possible norm waiting time reduction

$$
\left(W-W_{i}\right) / W ; \quad i=1,2
$$

As mentioned before we are interested in how far the waiting time can be reduced, expressed as a percentage of the largest possible reduction, by using a certain norm waiting time reduction for orders for products of category 1 . These percentages were calculated (see Appendix) and are shown graphically in Figs 2 to 4. It can be concluded from these figures that up to a certain value of the norm waiting time reduction (about $60 \%$ ) there is an approximately one-to-one relation between the norm waiting time reduction and the normalized actual waiting time reduction. This is confirmed by a number of other simulations which we have done using other starting values of the

\begin{tabular}{cccc}
\hline $\begin{array}{c}\text { Utilization rate } \\
(\%)\end{array}$ & $\lambda_{1}=\lambda_{2}$ & $\lambda_{1}=\frac{1}{2} \lambda_{2}$ & $\lambda_{1}=\frac{1}{4} \lambda_{2}$ \\
\hline 84 & 5.48 & 4.56 & 4.13 \\
89 & 6.46 & 5.26 & 4.77 \\
95 & 7.48 & 6.15 & 5.48 \\
\hline
\end{tabular}

Table 4. Category 1 absolute priority waiting times. 


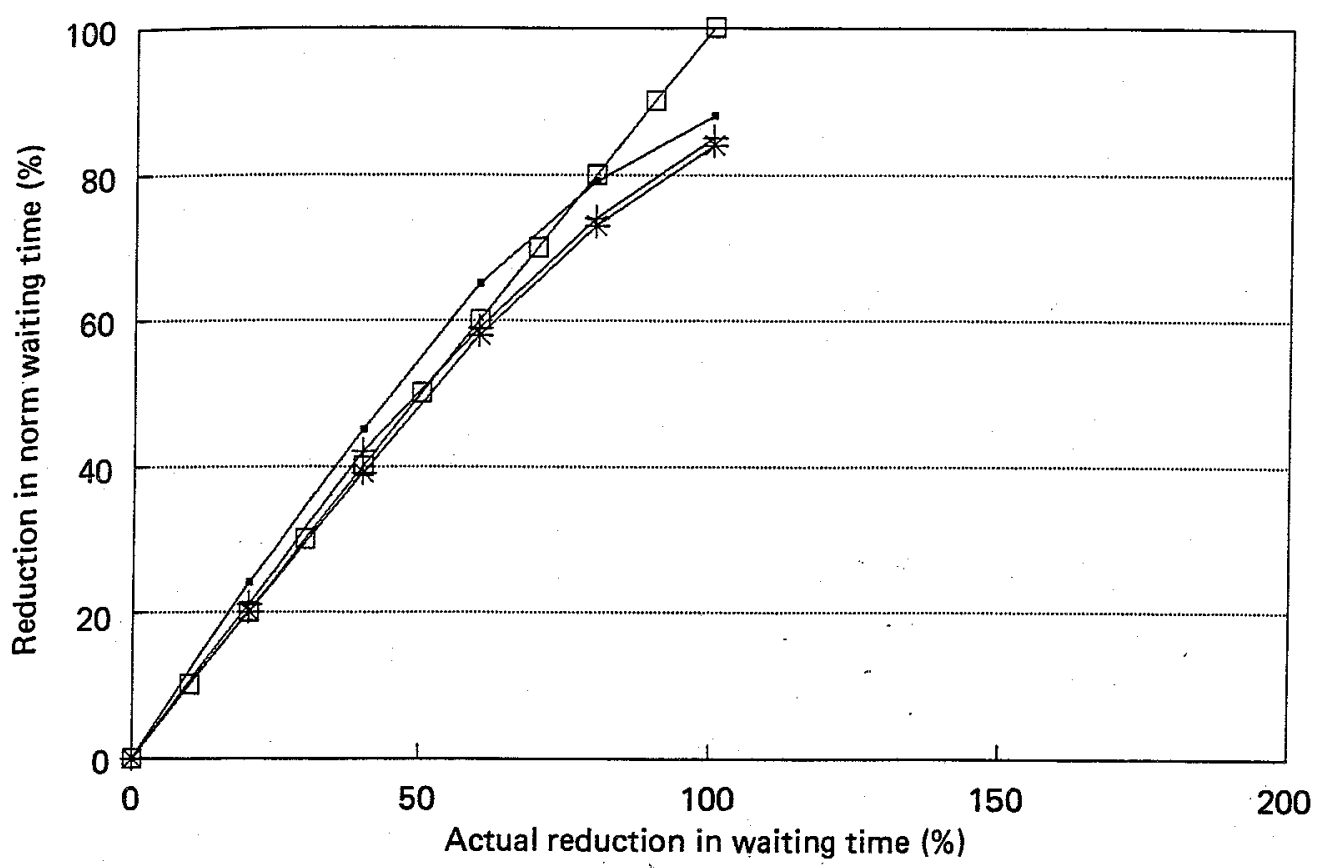

Figure 2. Actual waiting time reduction as a function of norm waiting time reduction; utilization rate $84 \%$ ( (E) $\lambda_{1}=\lambda_{2} ;(+) \lambda_{1}=\frac{1}{2} \lambda_{2} ;(*) \lambda_{1}=\frac{1}{4} \lambda_{2}$.

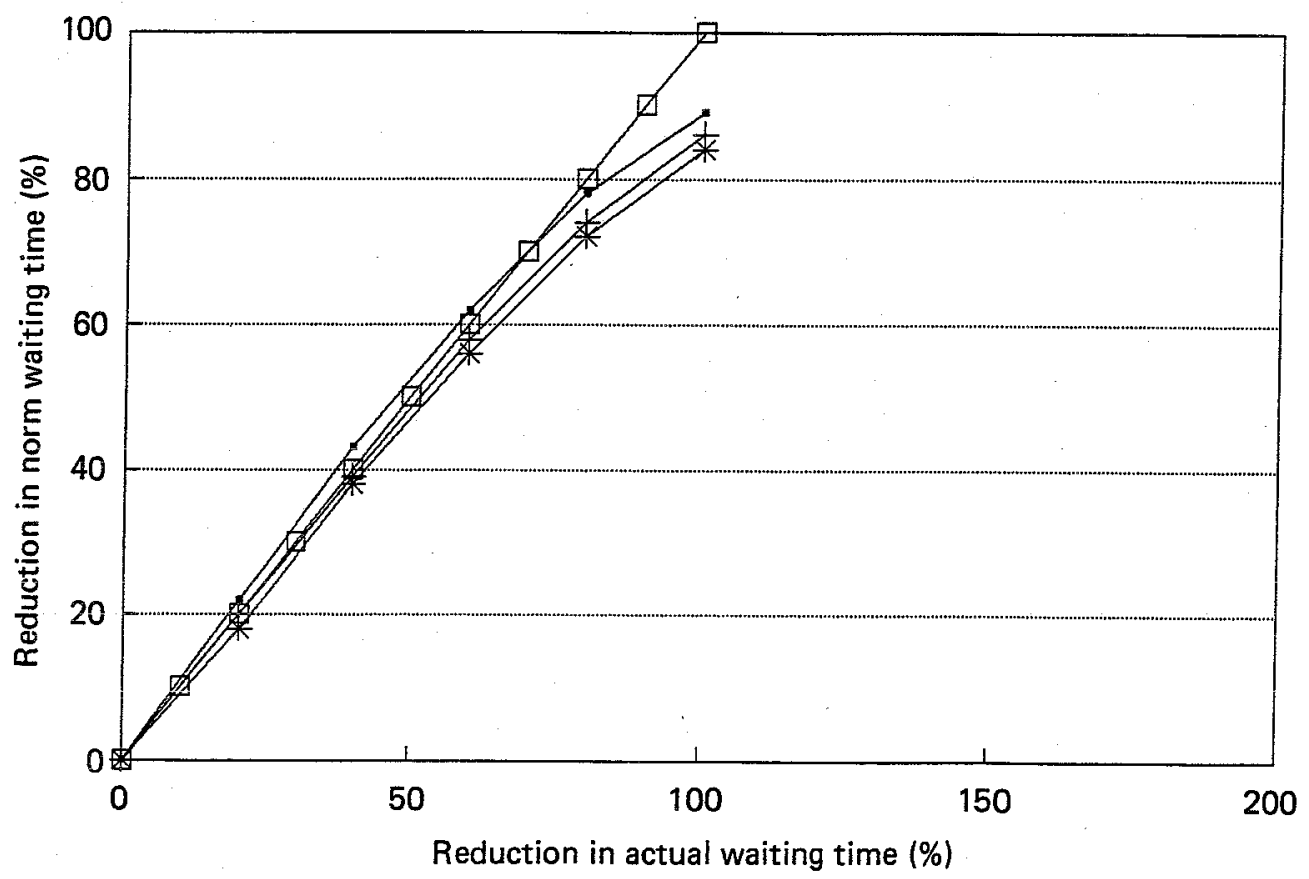

Figure 3. Actual waiting time reduction as a function of norm waiting time reduction; utilization rate $89 \% \cdot(\approx) \lambda_{1}=\lambda_{2} ;(+) \lambda_{1}=\frac{1}{2} \lambda_{2} ;(*) \lambda_{1}=\frac{1}{4} \lambda_{2}$. 


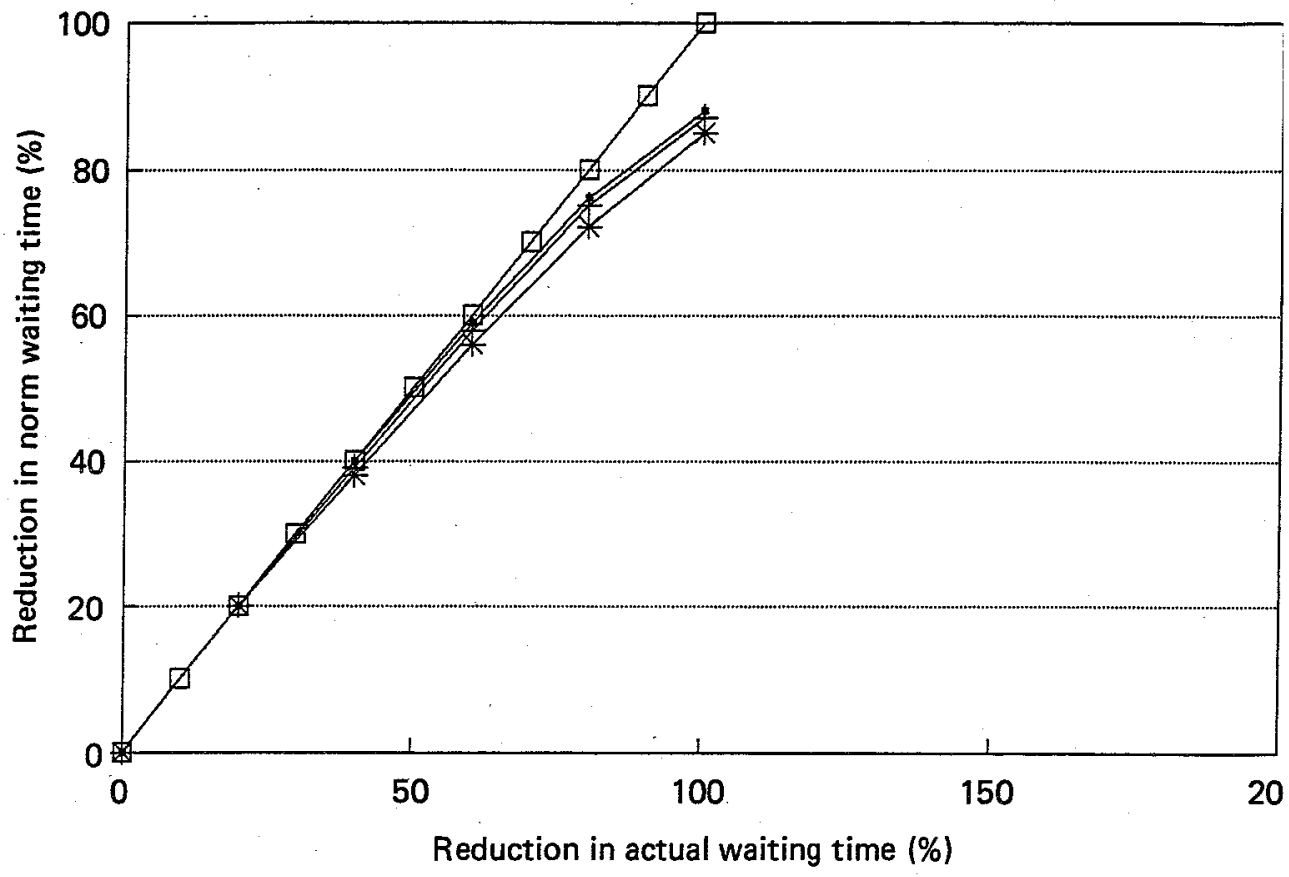

Figure 4. Actual waiting time reduction as a function of norm waiting time reduction; utilization rate $95 \%$ ( (a) $\lambda_{1}=\lambda_{2} ;(+) \lambda_{1}=\frac{1}{2} \lambda_{2} ;(*) \lambda_{1}=\frac{1}{4} \lambda_{2}$.

random number generators. Therefore, for practical purposes, in the case where we have two categories, we can state that to attain a normalized waiting time reduction of $x \%(0 \leqslant x \leqslant 60)$ for one of the categories, we must decrease the norm waiting time for this category by $x \%$ and increase the norm waiting time for the other category such that eqn. 2 holds. Then using the operation due-date sequencing.rule it is guaranteed that the reduction will be obtained and, moreover, that it will be obtained in a controlled way (small variance in waiting time) at the order level.

\section{Conclusions}

We have derived a method which makes it possible to create different predictable flow rates for production orders of different product categories. This method has been tested via the simulation of a job shop with two different flow rates. We used only two flow rates because this is generally the situation in practical applications: repair orders vs. normal orders, rush orders vs. normal orders, engineering orders vs. normal orders, etc. The results of the simulation study show that it is possible to create in a simple way different predictable flow rates for different categories of work orders in production departments. Our method requires that the average work order flow rate is controlled. This can be achieved via input/output planning, or work-load control.

We have further demonstrated that, over a wide range of values (up to $c .60 \%$ of the average waiting time) the differences in waiting times (and thus in flow rates) that can be achieved can be calculated by means of a simple balance equation (see eqn. 2).

Via computer simulation we have shown that the system can be 'forced' to realize these different flow rates, and, therefore, produce different throughput times, by using operation due-date sequencing as a priority rule. These results seem to be rather 
insensitive to the overall capacity utilization rate of the system and to the relative densities of the order categories involved. Of importance in the application of the proposed method is the observation that the validity of the balance equation mentioned above is particularly strong for high utilization rates.

Finally, we have observed that, when using different flow rates, there always is difference between the normative flow rates and the actual flow rates. For example, it can be seen from Table 3 that when $\lambda_{1}=\lambda_{2}$ a waiting time norm of $14.10(80 \%$ of the FCFS waiting time) must be assigned in order to achieve an actual waiting time of 14.82 ( $83 \%$ of the FCFS waiting time). The general observation is that the fast product category always lags behind schedule and the slow product category is always ahead of schedule. This is an important piece of knowledge for scheduling in practice. When the scheduled flow times of the orders differ from the average flow time in the system, there is always a systematic difference between the scheduled due-date and the actual duedate. However, this difference can be estimated (see for instance Table 1) and, therefore, can be accounted for when predicting external due-dates.

The results reported in this paper provide a strong theoretical and practical basis for controlling work order throughput times and improving due-date reliability in situations where differences in flow rates between order categories are required. However, further research is required in order to extend the principles to different situations and to test the implementation of the method in practice.

\section{References}

BAKER, K., 1974, Introduction to Sequencing and Scheduling (New York: Wiley).

BAKER, K. R., 1984, The effects of input control in a simple scheduling model. Journal of Operations Management, 4, 99-112.

BЕСHTE, W., 1982, Controlling manufacturing leadtime and work-in-process inventory by means of load oriented order release. APICS Conference Proceedings.

BERTRAND, J. W. M., 1985, Multiproduct optimal batch sizes with in-process inventories and multi work centres. IIE Transactions, 17, 157-163.

BERTRAND, J. W. M., and WorTMANN, J. C., 1981, Production Control and Information Systems for Component Manufacturing Shops (Ámsterdam: Elsevier).

Conway, R. W., MAXwell, W. L., and MilleR, L. W., 1967, Theory of Scheduling (New York: Addison-Wesley).

EILON, S., and ChOWDHURy, I. G., 1976, Due dates in job shop scheduling. International Journal of Production Research, 14, 223-237.

KANET, J. J., 1982, Towards understanding leadtimes in MRP systems. Production and Inventory Management, 23 (3), 1-14.

KANET, J. J., and HAYYA, J. C., 1982, Priority dispatching with operation due dates in job shop. Journal of Operations Management, 2, 167-175.

KARMARKAR, U. S., 1987, Lot sizes, lead times and in-process inventories. Management Science, $33,409-418$.

MATHER, H., 1984, How to Really Manage Inventories (New York: McGraw-Hill).

PlossL, G. W., and WELCH, W. E., 1979, The Role of Top Management in the Control of Inventory (New York: Prentice Hall).

Plossi, G. W., 1988, Throughput time control. International Journal of Production Research, 26, 493-499.

Solberg, J. J., 1981, Capacity planning with a stochastic workfiow model. AIIE Transactions, $13,116-122$.

STECKE, K. E., and SOLBERG, J. J., 1981, Loading and control policies for a flexible manufacturing system. International Journal of Production Research, 19, 481-490.

TAtsiopoulos, I. P., and KingSman, B. G., 1983, Lead time management. European Journal of Operational Research, 14, 351-358. 
Appendix

\begin{tabular}{|c|c|c|c|c|c|c|c|c|c|}
\hline \multirow{3}{*}{$\begin{array}{c}\text { Reduction } \\
\text { in norm } \\
\text { waiting time } \\
(\%)\end{array}$} & \multicolumn{9}{|c|}{ Utilization rate $(\%)$} \\
\hline & \multicolumn{3}{|c|}{84} & \multicolumn{3}{|c|}{89} & \multicolumn{3}{|c|}{95} \\
\hline & A & B & $\mathrm{C}$ & A & B & $\mathrm{C}$ & $\mathbf{A}$ & B & $\mathrm{C}$ \\
\hline 0 & 0 & 0 & 0 & 0 & 0 & 0 & 0 & 0 & 0 \\
\hline 20 & 24 & 21 & 20 & 22 & 20 & 18 & 20 & 20 & 20 \\
\hline 40 & 45 & 42 & 39 & 43 & 39 & 38 & 40 & 39 & 38 \\
\hline 60 & 65 & 59 & 58 & 62 & 58 & 56 & 59 & 58 & 56 \\
\hline 80 & 79 & 74 & 73 & 78 & 74 & 72 & 76 & 75 & 72 \\
\hline 100 & 88 & 85 & 84 & 89 & 86 & 84 & 88 & 87 & 85 \\
\hline
\end{tabular}

Table A1. Reduction in waiting time, as a percentage of the greatest possible reduction, for all simulated situations: (A) $\lambda_{1}=\lambda_{2} ;$ (B) $\lambda_{1}=\frac{1}{2} \lambda_{2} ;$ (C) $\lambda_{1}=\frac{1}{4} \lambda_{2}$.

We give an example of the calculations used to derive the values listed in Table A1. For a shop utilization rate of $84 \%$ and $\lambda_{1}=\lambda_{2}$, the total (shop) waiting time if all orders have the same norm waiting time is 17.75 (see Table 1). The total waiting time if all orders of product category 1 always have priority over orders of product category 2 is $5 \cdot 48$. Therefore, the greatest possible reduction in waiting time that can be obtained is

$$
17 \cdot 75-5 \cdot 48=12 \cdot 27
$$

Using a norm waiting time for product category 1 orders of $60 \%$ of the average waiting time, the total actual waiting time for product category 1 orders is 12.25 time units.

The actual reduction in total waiting time expressed as a fraction of the greatest possible reduction is thus

$$
(17 \cdot 75-12 \cdot 25) /(17 \cdot 75-5 \cdot 48)=0 \cdot 448 \simeq 0 \cdot 45
$$

